\title{
Effect of graphite oxide on photodegradation behavior of poly(vinyl alcohol)/graphite oxide composite hydrogels
}

\author{
Young-E Moon, Jumi Yun, Hyung-Il Kim and Young-Seak Lee \\ Department of Fine Chemical Engineering and Applied Chemistry, BK21-E²M, Chungnam National University, Daejeon 305-764, \\ Korea
}

\author{
Article Info \\ Received 20 April 2011 \\ Accepted 23 May 2011 \\ *Corresponding Author \\ E-mail: hikim@cnu.ac.kr \\ Tel: +82-42-821-6694 \\ Open Access \\ DOI: http://carbonlett.org/ \\ 10.5714/CL.2011.12.3.138 \\ This is an Open Access article distributed \\ under the terms of the Creative Commons \\ Attribution Non-Commercial License \\ (http://creativecommons.org/licenses/ \\ by-nc/3.0/) which permits unrestricted \\ non-commercial use, distribution, and \\ reproduction in any medium, provided \\ the original work is properly cited.
}

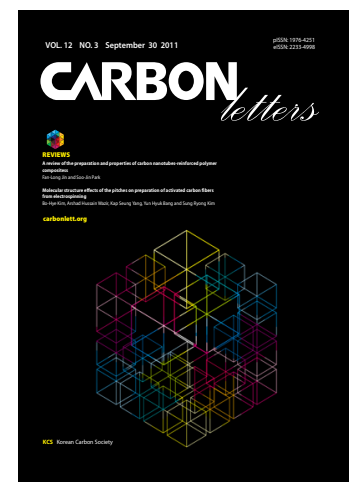

http://carbonlett.org

pISSN: 1976-4251

elSSN: 2233-4998

Copyright $\odot$ Korean Carbon Society

\begin{abstract}
Poly(vinyl alcohol) (PVA) composites with various graphite oxide (GO) contents (0 to 10 wt $\%$ ) were prepared by sonicating the mixture of PVA and GO, followed by crosslinking with glutaraldehyde. $\mathrm{GO}$ was pre-treated with oxyfluorination $\left(\mathrm{O}_{2}: \mathrm{F}_{2}=8: 2\right)$ in order to modify the surface of GO to allow it to carry hydrophilic functional groups. PVA/GO composite hydrogels were characterized by scanning electron microscopy and Fourier-transform infrared spectrometer (FT-IR). The morphology of the PVA/GO composite hydrogels and the variations in soluble gel portion were investigated under various GO contents and UV irradiation doses. The variation in the chemical structure of photo degraded PVA/GO composite hydrogels was studied by FT-IR. The photochemical stability of PVA/GO composite hydrogels under UV irradiation was found to improve noticeably with increasing content of uniformly dispersed GO.
\end{abstract}

Key words: photochemical stability, graphite oxide, poly(vinyl alcohol)

\section{Introduction}

The polymeric composites have attracted much interest in several fields [1,2]. Polymers reinforced with various fillers have found numerous applications in the household, industrial and military fields. Especially, nanocomposites containing low amounts of nano-sized additives in the polymer matrix have been studied extensively [3-7]. The main advantages of nanocomposites are their high thermal and mechanical properties, reduced flammability, and better barrier properties when compared to those properties of unfilled polymers. The proper combination of polymer matrix with additives has been reported to be important for the above mentioned properties $[8,9]$.

However, the photochemical properties of polymeric composites have not been well documented so far. It has been reported in a few recent publications that the photo oxidation in polymer nanocomposites was faster than that in an unfilled matrix due to the reduction of degradation induction time [10,11]. The photochemical stability of poly(vinyl alcohol) (PVA) can be modified by the addition of small amounts of other components. Sionkowska reported that PVA/collagen blends showed more highly improved thermal and photochemical stability than the single component did [12].

PVA is a water-soluble synthetic polymer with a high hydrophilicity, good biocompatibility, and non-toxicity. PVA is used in warp sizing, paper coating agents, adhesives, carriers in drug delivery, and as a component of biomedical and packaging material [13]. The mixing of PVA with inorganic fillers is generally carried out to improve its properties. One of the popular modifiers is carbon material, which can be used in various polymorphic forms, such as carbon black, carbon nanotubes, and graphite [14,15]. Recently, graphite oxide (GO) has attracted a great deal of attention due to its unique structural and electrical properties. 
GO, which is prepared by the oxidation of graphite, has a layered structure composed of parallel pseudo two-dimensional lamellae. Each layer consists of randomly distributed unoxidized aromatic regions and six-member aliphatic regions attached with polar groups, such as hydroxyl, epoxide, ether, and carboxyl groups, as a result of oxidation [16]. GO has intercalated or exfoliated structures in the polymer matrix that create a nanocomposite similar to montmorillonite $[17,18]$. In addition, GO can impart an electric conductivity to the polymer composites [19] and can be used as a host material for the synthesis of conducting polymer intercalated nanocomposites $[20,21]$.

In this study, we prepared PVA/GO composite hydrogels with various content of $\mathrm{GO}$. GO was pre-treated with oxyfluorination $\left(\mathrm{O}_{2}: \mathrm{F}_{2}=8: 2\right)$ in order to create the hydrophilic functional groups on the layers. The photochemical stability of the PVA/ GO composites was investigated in terms of morphology and content of GO.

\section{Experimental}

\subsection{Materials}

PVA (molecular weight $31000-50000 \mathrm{~g} / \mathrm{mol}$ ) and glutaraldehyde (GA) were purchased from Sigma-Aldrich Chemical (USA). GO was prepared by Hummers method using graphite obtained from Samchun Chemical (Korea). Graphite was oxidized by fuming nitric acid and sulphuric acid. $\mathrm{HCl}(35 \%)$ was used as a catalyst.

\subsection{Preparation of oxyfluorinated GO}

Oxyfluorination of GO was performed to modify the surface properties of GO. Oxyfluorination was carried out at 1 bar for 3 min with an oxygen to fluorine gas ratio of 8:2. The surface of GO was modified to carry hydrophilic functional groups by oxyfluorination, resulting in the improved dispersion of GO in hydrophilic media.

\subsection{Preparation of PVA/GO composite hydrogel}

PVA solution $(10 \mathrm{wt} \%, \mathrm{w} / \mathrm{v})$ was prepared by dissolving PVA in distilled water at $90^{\circ} \mathrm{C}$ for $6 \mathrm{~h}$ and subsequent cooling to room temperature. Various GO dispersions $(1,3,5$, and 10 $\mathrm{wt} \%$ ) were prepared in $3 \mathrm{~mL}$ water by sonicating for $60 \mathrm{~min}$. PVA/GO composite hydrogels were prepared from the component mixtures produced by mixing $25 \mathrm{~mL}$ of PVA solution with $3 \mathrm{~mL}$ GO dispersion under sonication for another $60 \mathrm{~min}$, fol-

Table 1. Classifications of PVA/GO composite hydrogels

\begin{tabular}{cccccc} 
& GO 0 & GO 1 & GO 3 & GO 5 & GO 10 \\
\hline $\begin{array}{c}\text { PVA (10 wt } \%) \\
(\mathrm{mL})\end{array}$ & 25 & 25 & 25 & 25 & 25 \\
GO (g) & 0 & 0.025 & 0.075 & 0.125 & 0.250 \\
\hline
\end{tabular}

PVA: poly(vinyl alcohol), GO: graphite oxide. lowed by mixing with $\mathrm{GA}(0.5 \mathrm{~mL})$ and $\mathrm{HCl}$ for $5 \mathrm{~min}$ at room temperature. PVA/GO composite hydrogels were obtained by crosslinking PVA in $10 \mathrm{~mL}$ of component mixture on the petridish at $60^{\circ} \mathrm{C}$. The various $\mathrm{PVA} / \mathrm{GO}$ composite hydrogels are classified in Table 1 .

\subsection{Characterization}

The X-ray diffraction (XRD) patterns of the carbon materials were obtained by using a D8 ADVANCE (Bruker AXS, Germany) equipped with $\mathrm{Cu}$ radiation under $2 \theta$ ranges from $5^{\circ}$ to $80^{\circ}$, a step size of $0.02^{\circ}$, and a step time of $3 \mathrm{~s}$.

A Fourier-transform infrared spectrometer (FT-IR) FTS-175C (Cambridge, USA) was used to investigate the functional groups of oxyfluorinated GO and PVA/GO composite hydrogels. The FT-IR spectra of the PVA/GO composite hydrogels before and after UV irradiation were studied in the range of $400-4000 \mathrm{~cm}^{-1}$. The yield of photo oxidative degradation was determined based on the carbonyl and vinyl indices.

The surface morphology of the PVA/GO composite hydrogels was observed using a field emission scanning electron microscope (FE-SEM) S-5500 (Hitachi, Japan). As a pretreatment, every sample was sputter coated with osmium and placed under room vacuum to take FE-SEM images. The FE-SEM images were obtained at $10 \mathrm{keV}$.

The photochemical stability of the PVA/GO composite hydrogels was determined using FT-IR and a certain amount of soluble gel. The amount of soluble gel was measured with the weight changes before and after UV irradiation of each sample. After UV irradiation, the composite hydrogel was immersed in deionized water for $24 \mathrm{~h}$ to dissolve the photo decomposed gels. After separation and washing, the insoluble gel was dried to a constant weight and was weighed.

\subsection{UV irradiation}

The PVA/GO composite hydrogels were exposed to a lowpressure mercury vapor lamp (254 nm of wavelength) at room temperature. UV doses of irradiation were in the range of $0-2000$

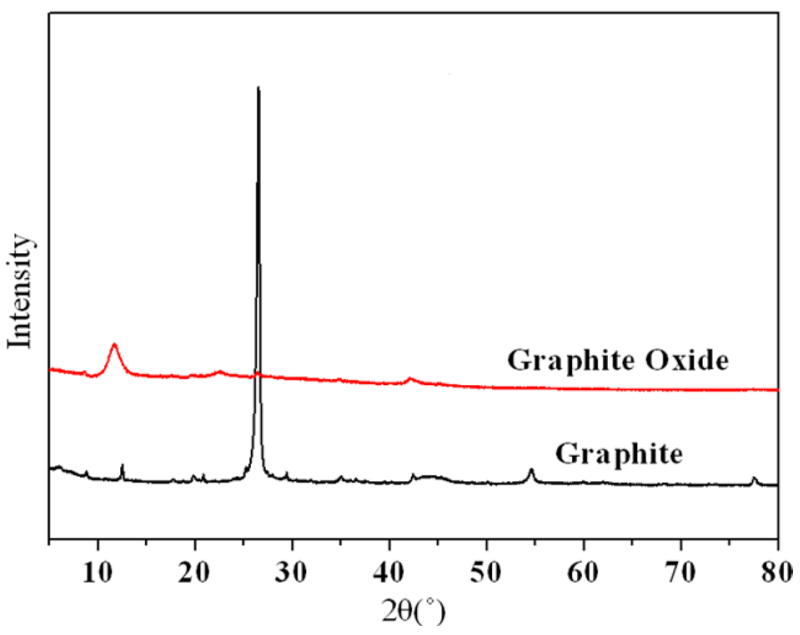

Fig. 1. X-ray diffraction patterns of graphite and graphite oxide. 


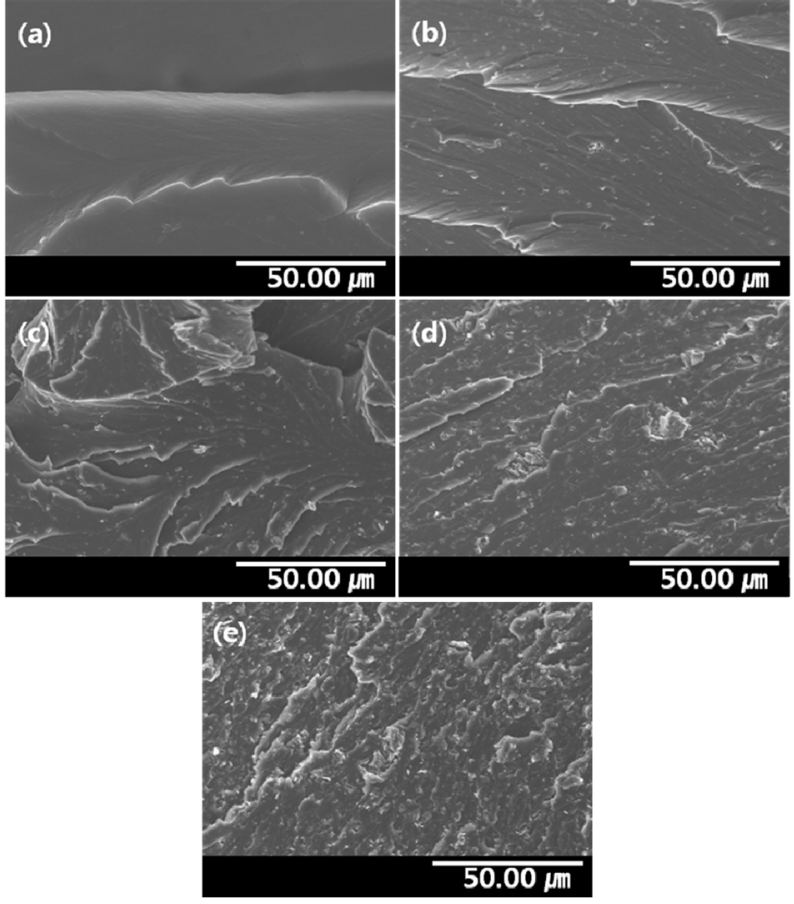

Fig. 2. Field emission scanning electron microscope micrographs of PVA/GO composite hydrogels; (a) GO 0, (b) GO 1, (c) GO 3, (d) GO 5, and (e) GO 10. PVA: poly(vinyl alcohol), GO: graphite oxide.

$\mathrm{kJ} / \mathrm{m}^{2}$. Distance between sample and light source was $5 \mathrm{~cm}$.

\section{Results and Discussion}

\subsection{Structural analysis of graphite and GO}

The XRD patterns of graphite and GO are shown in Fig. 1. The main peak positions were located at $2 \theta$ values of $26.5^{\circ}$ and $10.2^{\circ}$, indicating the graphite and GO, respectively. The diffraction peak of graphite, at around $2 \theta=26.5^{\circ}$, disappeared after the oxidation process and a new one arose at around $2 \theta=10.2^{\circ}$. However, the new peak was much broader and less intense than that observed for the pristine graphite because the oxidation of graphite resulted in a greater change in crystalline phase and layers of graphite structures.

\subsection{Surface morphology of PVA/GO composite hydrogels}

SEM was used to characterize the cross-sectional surface of the PVA/GO composite hydrogels. The SEM images of the PVA/GO composite hydrogels are presented in Fig. 2. GO was uniformly distributed in the PVA matrix due to the hydrophilic modification of the GO surface by oxyfluorination. GO was found in the hydrogel matrices without any noticeable crevice between the hydrogel and GO, demonstrating the good interfacial adhesion. A increased quantity of uniformly embedded GO was observed in the composite as the content of GO increased, although some agglomeration occurred for GO 10.

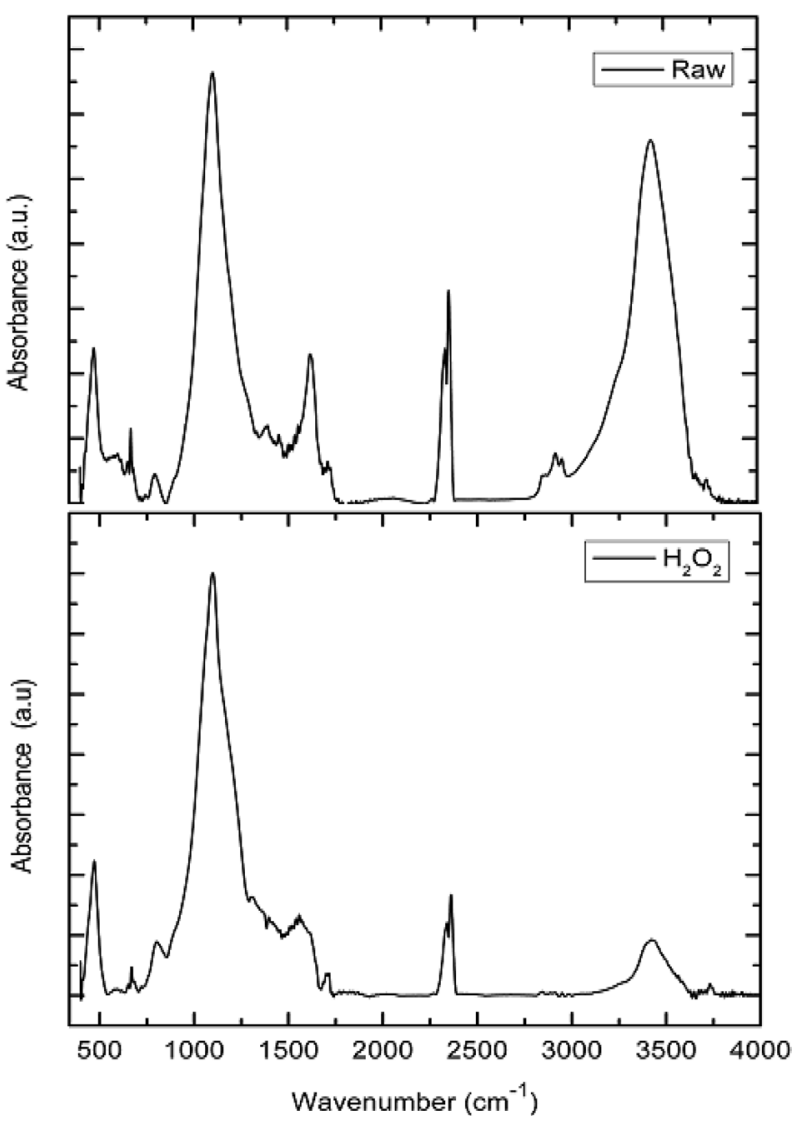

Fig. 3. Fourier-transform infrared spectrometer spectra of PVA and PVA/ GO composite hydrogel. PVA: poly(vinyl alcohol), GO: graphite oxide.

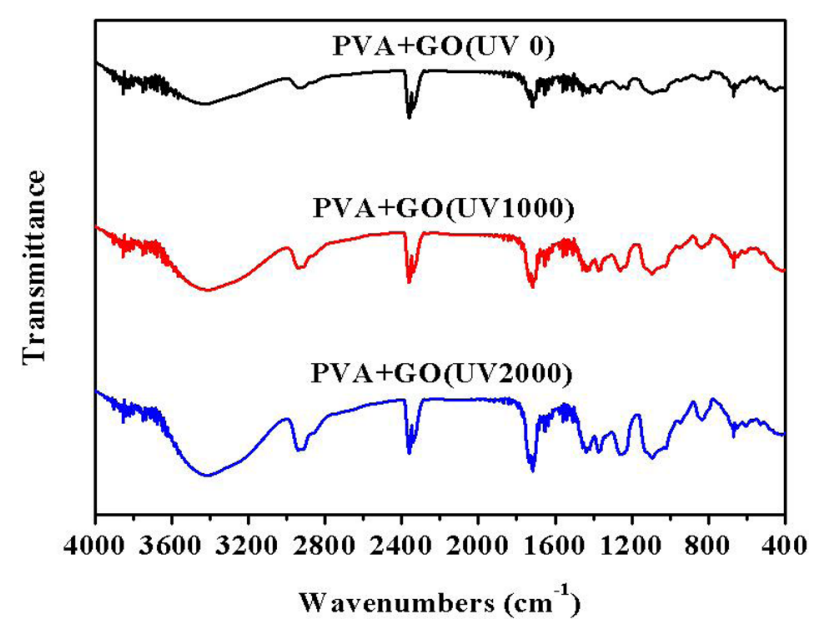

Fig. 4. Variations in Fourier-transform infrared spectrometer spectra of PVA/GO composite hydrogel (GO 5) under UV-irradiation doses of 0,1000 , and $2000 \mathrm{~kJ} / \mathrm{m}^{2}$. PVA: poly(vinyl alcohol), GO: graphite oxide.

\subsection{Effect of photo oxidation with UV irradiation on chemical structure variation of PVA hydrogel}

FT-IR spectra give additional information about the structure 


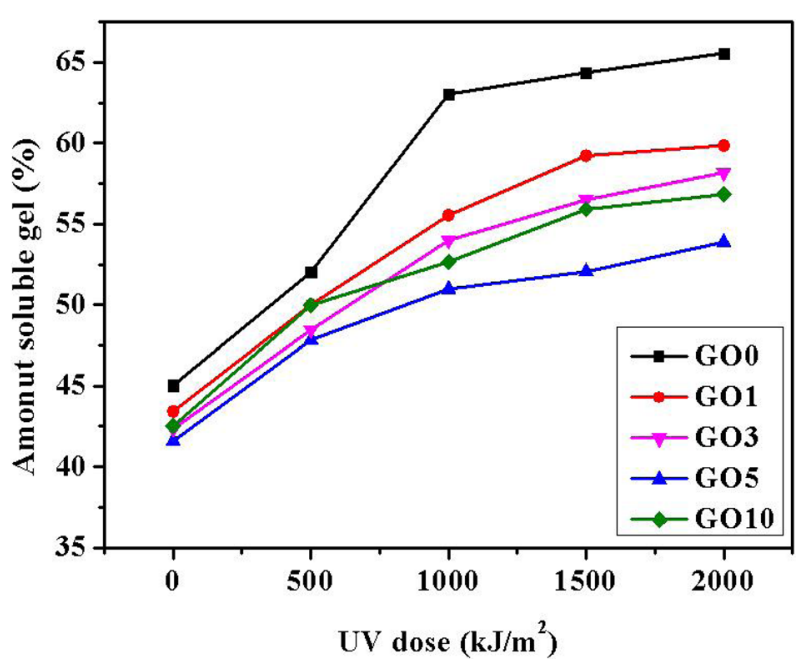

Fig. 5. Variations in amount of soluble gel for PVA/GO composite hydrogels containing various amounts of GO depending on UV-irradiation doses. PVA: poly(vinyl alcohol), GO: graphite oxide.

of PVA/GO composites. As can be seen in Fig. 3, the PVA hydrogel exhibited typical bands indicating the vinyl polymers. Bands at $2800-3000 \mathrm{~cm}^{-1}$ were due to stretching vibrations of the $\mathrm{CH}$ and $\mathrm{CH}_{2}$ groups and bands present at $1300-1500 \mathrm{~cm}^{-1}$ range were attributed to the $\mathrm{CH} / \mathrm{CH}_{2}$ deformation vibrations. The broad and intensive bands observed at $3000-3600 \mathrm{~cm}^{-1}$ were thought to be due to the hydroxyl groups. The C-O stretching band was observed at $1000-1260 \mathrm{~cm}^{-1}$. A less intensive carbonyl band, which resulted from the residual acetate groups during the synthesis of PVA, was detected at $1735 \mathrm{~cm}^{-1}$.

All these characteristic bands were also present in the PVA/ GO composite hydrogels. However, some shifts in both hydroxyl and carbonyl absorption bands to the lower wavelength were found in the spectra of the PVA/GO composite hydrogel, which suggests that intermolecular interactions, such as hydrogen bonds, formed between the PVA and the surface modified GO. UV irradiation on the PVA/GO composite hydrogels even caused significant changes in their FT-IR spectra due to the extensive photo oxidation. The variations in the FT-IR peaks of the PVA/ GO composite hydrogel under UV irradiation are shown in Fig. 4. The peak intensities of both the hydroxyl and carbonyl groups increased significantly with the increasing UV irradiation doses. The photo oxidation of the PVA matrix with UV irradiation was mainly responsible for the change in the content of the functional groups generated in the PVA/GO composite hydrogels.

\subsection{Effect of GO on photo-stability of PVA hy- drogel}

The amount of soluble gel usually increases as the photo-degradation of PVA is carried out by UV irradiation. The variations in the amount of soluble gel, depending on both amount of GO and UV irradiation dose, are shown in Fig. 5. The photo-degradation of PVA containing no GO showed an amount of soluble gel up to $65 \%$ at a UV irradiation dose of $2000 \mathrm{~kJ} / \mathrm{m}^{2}$. The amount of soluble gel decreased significantly over the broad range of UV irradiation for the various PVA/GO composite hydrogels as the content of GO increased. Especially, GO 5 composite hydrogel showed an amount of soluble gel of $53 \%$ at a UV irradiation dose of $2000 \mathrm{~kJ} / \mathrm{m}^{2}$. However, the GO 10 composite hydrogel was not so effective as GO 5 in improving the photo-stability of the PVA hydrogel due to the agglomeration of GO. The uniformly distributed GO in the PVA/GO composite hydrogel played a crucial role in improving the photo-stability of the PVA hydrogels.

\section{Conclusions}

PVA/GO composite hydrogels were prepared by crosslinking with GA. GO was produced by the Hummers method. GO prepared with the oxidative method led to a noticeable change in the crystalline phase and layers of the graphite structures. Hydrophilic functional groups were introduced on the surface of the GO through oxyfluorination treatment. The oxyfluorinated GO was uniformly distributed in the PVA matrix due to the formation of favorable interactions between PVA and GO. The photo-degradation of PVA by UV irradiation caused an increase in the amount of soluble gel. The amount of soluble gel varied depending on both the amount of GO and the UV irradiation dose. The amount of soluble gel decreased from 65 to $53 \%$ for the PVA/GO composite at a UV irradiation dose of $2000 \mathrm{~kJ} / \mathrm{m}^{2}$, as the content of GO increased to $5 \mathrm{wt} \%$. The uniformly distributed $\mathrm{GO}$ in the PVA/GO composite hydrogel played a crucial role in effectively improving the photo-stability of the PVA hydrogels.

\section{References}

[1] Breuer O, Sundararaj U. Big returns from small fibers: a review of polymer/carbon nanotube composites. Polym Compos, 25, 630 (2004). http://dx.doi.org/10.1002/pc.20058.

[2] Endruweit A, Johnson MS, Long AC. Curing of composite components by ultraviolet radiation: a review. Polym Compos, 27, 119 (2006). http://dx.doi.org/10.1002/pc.20166.

[3] Kacperski M. Polymer nanocomposites. Part I. General characteristics, fillers and nanocomposites based on termosetting polymers. Polimery/Polymers, 47, 801 (2002).

[4] Sinha Ray S, Okamoto M. Polymer/layered silicate nanocomposites: a review from preparation to processing. Prog Polym Sci, 28, 1539 (2003). http://dx.doi.org/10.1016/j.progpolymsci. 2003.08.002.

[5] Pawlak A, Morawiec J, Piorkowska E, Galeski A. Nanocomposites of polypropylene and polyethylene with montmorillonite type clays. Polimery/Polymers, 49, 240 (2004).

[6] Kelar K, Jurkowski B, Mencel K. Montmorillonite separated from bentonite--ITS modification and possibility to USE in anionic polymerization of $\varepsilon$-caprolactam for preparation of nanocomposites. Polimery/Polymers, 50, 449 (2005).

[7] Golebiewski J, Rozanski A, Galeski A. Study on the process of preparation of polypropylene nanocomposite with montmorillonite. Polimery/Polymers, 51, 374 (2006)

[8] Uhl FM, Wilkie CA. Polystyrene/graphite nanocomposites: effect on thermal stability. Polym Degradation Stab, 76, 111 (2002). http://dx.doi.org/10.1016/s0141-3910(02)00003-4.

[9] Zhu J, Uhl FM, Morgan AB, Wilkie CA. Studies on the mechanism by which the formation of nanocomposites enhances thermal stability. Chem Mater, 13, 4649 (2001). http://dx.doi.org/10.1021/cm010451y. 
[10] Morlat-Therias S, Mailhot B, Gardette JL, Da Silva C, Haidar B, Vidal A. Photooxidation of ethylene-propylene-diene/montmorillonite nanocomposites. Polym Degradation Stab, 90, 78 (2005). http://dx.doi.org/10.1016/j.polymdegradstab.2005.01.040.

[11] La Mantia FP, Dintcheva NT, Malatesta V, Pagani F. Improvement of photo-stability of LLDPE-based nanocomposites. Polym Degradation Stab, 91, 3208 (2006). http://dx.doi.org/10.1016/j.polymdegradstab.2006.07.014

[12] Sionkowska A, Skopinska J, Wisniewski M. Photochemical stability of collagen/poly (vinyl alcohol) blends. Polym Degradation Stab, 83, 117 (2004). http://dx.doi.org/10.1016/s0141-3910(03)00232-5.

[13] Hassan C, Peppas N. Structure and applications of poly(vinyl alcohol) hydrogels produced by conventional crosslinking or by freezing/thawing methods. Biopolymers · PVA Hydrogels, Anionic Polymerisation Nanocomposites Advances in Polymer Science, Vol. 153, Springer Berlin, Heidelberg, 37 (2000). http://dx.doi.org/ 10.1007/3-540-46414-x 2

[14] Park YS, Huh M, Kang SJ, Lee SH, An KH. Parametric study on synthesis of carbon nanotubes by the vertical spray pyrolysis method. Carbon Lett, 12, 102 (2011). http://dx.doi.org/10.5714/ CL.2011.12.2.102

[15] Kwiecinska B, Petersen HI. Graphite, semi-graphite, natural coke, and natural char classification--ICCP system. Int J Coal Geol, $\mathbf{5 7}$ 99 (2004). http://dx.doi.org/10.1016/j.coal.2003.09.003.

[16] Szabo T, Berkesi O, Forgo P, Josepovits K, Sanakis Y, Petridis D, Dekany I. Evolution of surface functional groups in a series of progressively oxidized graphite oxides. Chem Mater, 18, 2740 (2006). http://dx.doi.org/10.1021/cm060258+.

[17] Hua L, Kai W, Inoue Y. Synthesis and characterization of poly( $\square-$ caprolactone)-graphite oxide composites. J Appl Polym Sci, 106, 1880 (2007). http://dx.doi.org/10.1002/app.26503.

[18] Uhl FM, Wilkie CA. Preparation of nanocomposites from styrene and modified graphite oxides. Polym Degradation Stab, 84, 215 (2004). http://dx.doi.org/10.1016/j.polymdegradstab.2003.10.014.

[19] Wang WP, Pan CY. Preparation and characterization of poly(methyl methacrylate)-intercalated graphite oxide/poly(methyl methacrylate) nanocomposite. Polym Eng Sci, 44, 2335 (2004). http:// dx.doi.org/10.1002/pen.20261.

[20] Wan YZ, Wang YL, Wen TY. Effect of specific surface area and silver content on bacterial adsorption onto $\mathrm{ACF}(\mathrm{Ag})$. Carbon, 37, 351 (1999). http://dx.doi.org/10.1016/s0008-6223(99)90001-5.

[21] Dutta K, De SK. Electrical conductivity and optical properties of polyaniline intercalated graphite oxide nanocomposites. J Nanosci Nanotechnol, 7, 2459 (2007). http://dx.doi.org/10.1166/jnn. 2007.429. 